\title{
A Curitiba dos Restaurantes: Uma análise da evolução dos estabelecimentos de alimentação comercial com base nos registros do Guia Quatro Rodas - 1989/2014.
}

\section{The Curitiba's Restaurants: An analysis of the evolution of commercial food establishments based on the Guia Quatro Rodas records - 1989/2014.}

\author{
Los restaurantes en Curitiba: Un análisis de la evolución de los \\ establecimientos comerciales de alimentos con base en los registros del Guía \\ Quatro Rodas - 1989/2014.
}

\author{
Camila Bizinelli ${ }^{1}$ \\ Franciele C. Manosso ${ }^{2}$ \\ Cinthia Maria de Sena Abrahão ${ }^{3}$ \\ José Manoel Gonçalves Gândara ${ }^{4}$
}

\begin{abstract}
Resumo: A gastronomia, discutida como um segmento que se encontra estreitamente arrolado ao turismo, pode ser observada tanto como um elemento integrador da infraestrutura turística, quanto um componente da oferta, ou seja, um fator motivador para a realização da viagem. Estudos que abordem essa temática por vieses distintos tornam-se relevantes. A presente pesquisa, então, tem como objetivo central a análise da dinâmica da distribuição dos restaurantes da cidade de Curitiba, bem como, das categorias de estabelecimentos presentes nos bairros, utilizando-se do Guia Quatro Rodas, em um período de 25 anos, considerando os guias de 1989, 2001 e 2014. Como metodologia de pesquisa utilizou-se a análise de conteúdo, bem como, as pesquisas bibliográfica e documental para o alcance do objetivo proposto. Como resultados pode-se observar que há uma concentração dos estabelecimentos no período analisado (1989/2001/2014), sobretudo, na região central da cidade e adjacências, bairro Batel, por exemplo, e também no bairro de Santa Felicidade, tradicionalmente conhecido e divulgado como atrativo gastronômico de Curitiba. E também, cabe destacar uma predominância de pizzarias, churrascarias e estabelecimentos que servem comida italiana, como principais categorias de restaurantes presentes na cidade.
\end{abstract}

Palavras-chave: Turismo; Gastronomia; Distribuição Espacial; Restaurantes; Curitiba - PR.

Abstract: The cuisine, discussed as a segment which is closely enrolled in the tourism, can be seen both as an integrating element of tourism infrastructure as a component of the offer, in other words, a motivating factor for the

\footnotetext{
${ }^{1}$ Graduação em Turismo (Bacharelado), Mestre em Geografia pela Universidade Federal do Paraná (UFPR), Chef de cozinha Nacional e Internacional pela Universidade Positivo. E-mail: ca_bizinelli@ @otmail.com

${ }^{2}$ Graduação em Turismo (Bacharelado), Mestre em Geografia pela Universidade Federal do Paraná (UFPR) e PósGraduanda em Plenajamento e Gestão de Negócios pela Universidade Positivo. Email: francimanosso@ gmail.com

${ }^{3}$ Graduada em Ciências Econômicas pela Universidade Federal de Uberlândia (1990), mestre em História Econômica pela Universidade de São Paulo (1998) e doutora em Geografia pela Universidade Federal do Paraná. Docente na área Gestão Empresarial pela Universidade Federal do Paraná, Setor Litoral e do Programa de Mestrado em Turismo da Universidade Federal do Paraná. E-mail: cisena@ @erra.com.br

${ }^{4}$ Graduação em Turismo (Bacharelado) pela UFPR. Mestrado em Gestão do Turismo pela Scuola Superiore del Commercio del Turismo i dei Servizzi de Milão. Doutorado em Turismo e Desenvolvimento Sustentável pela Universidad de Las Palmas de Gran Canária. Professor e Pesquisador do Departamento de Turismo, do curso de Graduação em Turismo, do Mestrado e Doutorado em Geografia e do Mestrado em Turismo da Universidade Federal do Paraná. E-mail: jmggandara@ yahoo.com.br
} 

análise da evolução dos estabelecimentos de alimentação comercial com base nos registros do Guia Quatro Rodas 1989/2014. Revista Hospitalidade. São Paulo, volume 13, pp. 0828, agosto de 2016 .

realization of the trip. Studies that address this issue by different biases become relevant. The present research, then, has as its central objective the analysis of the distribution's dynamics of the restaurants in the Curitiba's city, as well as the categories of establishments present in the districts, using the Guia Quatro Rodas, in a period of 25 years, considering the guides 1989, 2001 and 2014. The research's methodology used was the content analysis, as well as the literature and documents research to achieve the proposed objective research. In the results can be seen that there is a concentration of establishments in the analyzed period (1989/2001/2014), especially in the central region of the city and surroundings, Batel district, for example, and also in the Santa Felicidade neighborhood, traditionally known and disclosed as Curitiba's gastronomic attraction. Also, it is worth noting a predominance of pizzerias, steak houses and establishments that serve Italian food as the main categories of restaurants present in the city.

Key Words: Tourism; Gastronomy; Spatial Distribution; Restaurants, Curitiba - PR.

Resumen: La cocina, discutido como un segmento que está inscrito estrechamente en el turismo, puede ser visto tanto como un elemento integrador de la infraestructura turística, como un componente de la oferta, es decir, un factor de motivación para la realización del viaje. Los estudios que abordan este tema por diferentes sesgos vuelven relevantes. Esta investigación, entonces, tiene como objetivo central el análisis de la dinámica de la distribución de los restaurantes en la ciudad de Curitiba, así como las categorías de establecimientos presentes en los distritos, utilizando la Guía Quatro Rodas, en un período de 25 años, teniendo en cuenta los guías de 1989, 2001 y 2014 . La metodología de investigación utilizada fue el análisis de contenido, así como la bibliografía y documental para lograr el objetivo propuesto de investigación. En los resultados se pueden ver que hay una concentración de establecimientos en el período analizado (1989/2001/2014), especialmente en la región central de la ciudad y sus alrededores, distrito de Batel, por ejemplo, y también en el barrio de Santa Felicidade, tradicionalmente conocido y divulgado como atractivo gastronómico de Curitiba. Además, vale la pena destacar el predominio de pizzerías, casas de carne y establecimientos que sirven comida italiana como las principales categorías de restaurantes presentes en la ciudad.

Palabras Clave: Turismo; Gastronomía; Distribución Espacial; Restaurantes; Curitiba - PR.

\section{INTRODUÇÃo}

Duas características próprias ao turismo o diferenciam, nomeadamente, de outras atividades econômicas ou produtivas. A primeira delas é o fato deste ser uma prática social; a outra, e mais relevante, é o fato do espaço geográfico ser seu essencial objeto de realização (CRUZ, 2003). Contudo, cabe destacar o que Knafou (2001) discute a respeito da apropriação do espaço pelo turismo, fazendo com que sua função se altere. Tal processo é identificado pelo autor como a turistificação do espaço, que pode ser proveniente de três distintas fontes, sendo elas: o turista, o mercado e as ações dos planejadores e promotores territoriais.

Com base nessa relação entre o turismo e o espaço geográfico, propõe-se como objetivo central deste artigo analisar a evolução da 'dinâmica da distribuição espacial dos restaurantes da cidade de Curitiba, entre os anos de 1989 e 2014. Para esta análise, o universo de pesquisa está delimitado pelos restaurantes inclusos no Guia Quatro Rodas. Segundo Villanueva Ramos (2011), esta é uma fonte confiável e relevante, uma das mais antigas publicações brasileiras destinada a turistas (datando de 1966 sua primeira edição), abarcando informações sobre hotéis, restaurantes, atrações, entre outros, de mais de 800 cidades brasileiras. Considerando, ainda, que devido ao grande número de restaurantes encontrados na cidade, a escolha deste material como fonte da pesquisa deu-se pelo fato de congregar um número mais conciso de estabelecimentos, destacados e indicados aos visitantes de Curitiba.

Para tal, utilizam-se como metodologia, a pesquisa bibliográfica e documental, bem como, a análise de conteúdo do Guia Quatro Rodas, para que se possa observar efetivamente a evolução dos restaurantes no período de estudo proposto. 

análise da evolução dos estabelecimentos de alimentação comercial com base nos registros do Guia Quatro Rodas 1989/2014. Revista Hospitalidade. São Paulo, volume 13, pp. 0828, agosto de 2016

\section{A DINÂMICA ESPACIAL DO COMÉRCIO}

O espaço se constitui em um processo complexo, resultante da relação entre sociedade e ambiente (LAMAS, 2000; SANTOS E SERPA, 2000). Santos (1985), parte da concepção de que o espaço geográfico constitui uma realidade objetiva, um produto social em permanente processo de transformação. Consequentemente, para estudar o espaço geográfico, compete apreender a sua relação com a sociedade, pois é a discussão desse viés que apregoa à compreensão dos efeitos dos processos (refere-se ao aspecto temporal e mudanças da estrutura), e especifica as noções de forma (parte visível e o arranjo dos objetos físicos, se expressam na paisagem presente e em suas transformações), função (ligada à atividade para a qual a forma é designada, com a modificação da forma, a função se altera) e estrutura (diz respeito à interrelação entre as partes, é a matriz social onde as formas e funções são criadas e justificadas), como elementos fundamentais para a análise e compreensão da produção espacial (SANTOS, 1985).

De tal modo, "forma, função, processo e estrutura devem ser estudados concomitantemente e vistos na maneira como interagem para criar e moldar o espaço através do tempo". (SANTOS, 1997, p.52). Segundo Massey (2008), o espaço é o produto das inter-relações e interações que se estabelecem entre o global e o local; a esfera onde coexistem distintas - e dessemelhantes - trajetórias; e, por fim, trata-se de algo sempre em construção, em virtude de resultar da própria interação. O espaço seria, portanto, na concepção da referida autora, uma simultaneidade dinâmica, invariavelmente demudada pela inter-relacionalidade, isto é, pela constante espera da construção de novas relações.

A evolução humana fez com que o espaço geográfico fosse apropriado e modificado pelas sociedades. Logo, a distribuição espacial da humanidade, antes em pauta, sofreu uma mudança de abordagem, que passou a contemplar, também, a distribuição das atividades econômicas (PÍCOLLO, 2011). Assim, cabe salientar que, não basta identificar as transformações físicas que ocorrem nas aglomerações urbanas, tratando-as como evidências das mudanças no modo de uso do espaço. Mais que isso, é necessário verificar mudanças estruturais na vida social, que justificam a alteração na lógica de apropriação do espaço, transformando-o (OJIMA, 2006).

Sendo os restaurantes (objetos deste estudo) estabelecimentos de natureza comercial, fazse relevante abordar a dinâmica espacial do comércio nas cidades, pois, dentre todos os processos espaciais, um está associado especificamente às cidades: a formação/consolidação de estruturas comerciais e de serviços (SANTOS E SERPA, 2000). Pois, como afirma Godoy (2010), as atividades comerciais e de serviços, com seu desenvolvimento, adquiriram diversas formas de organização e apropriação do espaço, de acordo com as características socioculturais dos locais onde se desenvolvem.

Segundo Godoy (2010), a atividade varejista, para ofertar seus produtos, tende, geralmente, a agrupar-se/aglomerar-se. Tendência esta, que se justifica na medida em que ajuda a gerar forças de atração para os consumidores (sobretudo, pela variedade de produtos, serviços e preços ofertados), desencadeando impactos nos sistemas urbanos. Sendo que o principal, e mais visível, desses impactos é a apropriação e transformação dos espaços da cidade, adequando-os ao seu objetivo: a 'venda'. Alves e Ribeiro Filho (2008), ponderam que as atividades comerciais estão baseadas na economia de aglomeração e na variedade de produtos, o que desencadeia um poder estruturador - polarizador nos espaços onde estão instaladas.

De acordo com este viés, algumas preocupações pertinentes surgem calcadas nas tendências dos laços tradicionais entre o comércio - em especial o pequeno comércio varejista -, 

análise da evolução dos estabelecimentos de alimentação comercial com base nos registros do Guia Quatro Rodas 1989/2014. Revista Hospitalidade. São Paulo, volume 13, pp. 0828, agosto de 2016 .

e os centros das cidades estarem enfraquecendo nos últimos anos. Um dos fatores contribuintes para tal debilitação é representada pelo crescimento e expansão dos grandes projetos de comércio varejista, ou grandes superfícies comerciais, que se engastam de modo não integrado no contexto urbano (ESPINOSA SEGUÍ, 2003). Há, com isso, uma ameaça de que as cidades e suas áreas centrais deixem de ter significação como polo de compras, centro de integração social e difusor cultural. Esta ameaça é o resultado de mudanças estruturais no comércio varejista, resultantes da expansão de espaços e concentração de pontos de vendas (NÖRR STIEFENHOFER LUTZ, 2006).

O comércio, como elemento indissociável do fato urbano, ao definir contextos físicoespaciais que permitem interações entre os diversos atores locais, torna-se elemento fundamental para o entendimento das relações socioeconômicas urbanas. O que confere à atividade comercial um caráter que perpassa a função clássica de abastecimento de materiais e de serviços necessários à população local. Representa, pois, um cenário de construção da vida social pela viabilização de condições de integração sociocultural entre indivíduos e sua comunidade local. O comércio, portanto, demonstra ser uma das variáveis essenciais sobre a qual é possível atuar para fomentar, dinamizar, estruturar, impulsionar ou revitalizar as cidades (PROCOPIUCK E DJALO, 2008). Sendo assim, por meio da distribuição espacial das atividades econômicas, é possível verificar as suas repercussões e suas implicações na sociedade, considerando aspectos sociais, políticos, culturais e econômicos (SANTOS E SERPA, 2000; GODOY, 2010; PÍCOLLO, 2011).

$\mathrm{Na}$ sequência, tratar-se-ão do turismo e da alimentação, duas atividades socioeconômicas e culturais, que por este caráter, impactam diretamente no consumo e produção do espaço, sobretudo neste estudo, o espaço urbano.

\section{TURISMO E ALIMENTAÇÃO}

Fratucci (2008) afirma que o turismo deve ser entendido e compreendido como fenômeno produto de uma prática social, com intensas implicações espaciais. Fenômeno social, porque invariavelmente envolve pessoas (individualmente ou em grupos); e espacial, pois abrange sempre os deslocamentos e as ações destas pessoas pelo espaço percorrido e visitado. Esta definição se apoia no que afirma Moesch (2004), ao alegar que o turismo se compõe por meio de práticas histórico-sociais, que pressupõem o deslocamento de sujeito(s) em tempos e espaços, tornando-se, assim, o turismo uma prática social e um fenômeno, que permite afastamentos simbólicos do cotidiano.

Cabe lembrar que, por meio desta característica que o turismo possui, de fenômeno e prática social, diversos são os setores e segmentos que se emaranham em sua dinâmica, visando propiciar o pleno desenvolvimento de seu fundamental propósito, que é satisfazer as experiências do turista. Essa segmentação ocorre principalmente devido à demanda turística, que busca produtos e serviços diferenciados para se satisfazer. Para que essa demanda seja atendida, faz-se necessária a existência de uma oferta bem fomentada (BENI, 1998), na qual o turista possa encontrar tudo aquilo em que está interessado.

A gastronomia, então, pode ser vista como um dos segmentos que está estreitamente relacionado ao turismo, e que também é parte integrante da oferta turística, conformando-se não só como um componente da infraestrutura turística (um equipamento para uso dos turistas), mas, também, como a própria oferta turística, a motivação para ocasionar a viagem. E é sobre esta relação (turismo \& gastronomia) que se tratará a seguir (BIZINELLI, 2011).

Levando em consideração o que foi anteriormente exposto, a respeito do turismo e suas definições, bem como sua destacada ligação com diversos segmentos, inclusive o de alimentação, 

análise da evolução dos estabelecimentos de alimentação comercial com base nos registros do Guia Quatro Rodas 1989/2014. Revista Hospitalidade. São Paulo, volume 13, pp. 0828, agosto de 2016 .

cabe agora abordar mais profundamente esta relação. Um dos motivos desta abordagem é o fato de um dos segmentos do turismo que mais vem crescendo ser o de turismo gastronômico, como fica claro, por exemplo, no Overview do Turismo no Brasil (INMOBRASIL, 2011), que afirma verificar um aumento na demanda por alimentação, como pré-requisito na configuração de pacotes turísticos, da ordem de $67 \%$.

Verifica-se que a alimentação e o turismo são elementos complementares que abrem possibilidades de interações diversas, visando propiciar aos turistas uma experiência satisfatória e memorável. Com isso, o alimento torna-se, por assim dizer, um componente fundamental da experiência turística, podendo tanto saciar as necessidades fisiológicas, quanto conformar-se em um atrativo turístico (FAGLIARI, 2005).

Apesar destas duas possibilidades, em geral, enxerga-se a gastronomia como uma oferta técnica, um equipamento turístico. Todavia, é preciso atentar mais para o olhar que os turistas exercem sobre a gastronomia dos destinos que visitam, pois, em grande parte das viagens, um dos fatos mais rememorados são as experiências gastronômicas, ou seja, "momentos relacionados com o ato de se alimentar ficam marcados na memória dos turistas" (LOUZADA, 2006, P.12).

Como coloca Schlüter (2003), fica evidente que a questão alimentar, como parte integrante do legado cultural de uma sociedade, está adquirindo cada vez mais relevância como um produto turístico, ligado, sobretudo, ao turismo cultural. As principais motivações para este tipo de atividade são encontradas na busca do prazer por meio da alimentação e da viagem, dando preferência ao genuíno, em detrimento ao 'standard'; também, na curiosidade e desejo de compreender as raízes culinárias e a própria cultura local, por meio da gastronomia (motivação esta, que vem, constantemente, crescendo em importância).

Isso faz com que se reflita que a cultura de uma sociedade está, portanto, profundamente ligada à sua gastronomia e alimentação, levando este elo para além das formas de produção e consumo dos alimentos e bebidas, o que os torna parte integrante e fiel de sua cultura e identidade, conformando o patrimônio cultural que lhes diz respeito. Segundo o que nos coloca Onfray (1999), pode-se dizer que a questão alimentar é estética e filosófica, pois a cozinha relaciona-se com as práticas culturais das civilizações de todas as épocas, representando-as tanto quanto pinturas, esculturas ou a própria arquitetura.

Como exemplo disso, têm-se as famosas comidas e bebidas típicas, ou étnicas, que exercem seu poder de atração em turistas de todo mundo há muito tempo. Poder este, que com o passar do tempo transformou-se em um forte apelo ao turista que além de se interessar por locais diferenciados, culturas, paisagens, etc., passou, também, a se interessar pelos 'prazeres da boa mesa' (SCHLÜTER, 2003; BAHL, GIMENES E NITSCHE, 2011).

Além do que foi citado, e ainda nesta perspectiva cultural do turismo gastronômico, deve-se atentar para o que citam Gândara, Gimenes e Mascarenhas (2009), ao afirmarem que, de forma específica, o turismo gastronômico, ao considerar tanto a identidade cultural, quanto a perspectiva do consumo simbólico, ambas como atrativos turísticos, estimula o desenvolvimento de destinos e produtos, que são capazes de congregar características de valorização cultural, ao atendimento de uma demanda específica emergente.

Fagliari (2005) ainda coloca que a atratividade e o destaque que o ramo de alimentos e bebidas vem contraindo mediante os turistas, tornou-se uma questão focal na justificativa do desenvolvimento e utilização turística dos elementos gastronômicos. Verifica-se a relevância da alimentação como item respeitável do desenvolvimento turístico, desde sua perspectiva 
BIZINELLI, C; MANOSSO, F.C; ABRAHÃO, C. M. S.; GÂNDARA, J.M.G. A Curitiba dos Restaurantes: Uma análise da evolução dos estabelecimentos de alimentação comercial com base nos registros do Guia Quatro Rodas 1989/2014. Revista Hospitalidade. São Paulo, volume 13, pp. 0828, agosto de 2016.

contributiva para a economia dos destinos turísticos, até seu caráter cultural e patrimonial, como fonte de diversificação da oferta e motivadora de demandas específicas.

Vistas as abordagens realizadas no referencial teórico deste artigo, a seguir será apresentado o panorama da alimentação em Curitiba, assim como as principais informações sobre a cidade.

\section{CURITIBA E O SETOR DE ALIMENTAÇÃO}

Curitiba é a capital do Paraná, um dos três estados que compõem a região sul do Brasil. Segundo dados do IBGE (2010) a cidade abriga 1.751.907 habitantes e possui uma das maiores concentrações de áreas verdes por habitante (cerca de $51 \mathrm{~m}^{2} /$ habitante), apesar de estar $100 \%$ inserida no meio urbano (IBGE, 2010). Conforme a Prefeitura Municipal de Curitiba (2012), a cidade está dividida em 75 bairros (Figura 1), sendo estes distribuídos por seus 435,274 km² de área. 


\section{HOSPITALIDADE}

ISSN 1807-975X
BIZINELLI, C; MANOSSO, F.C; ABRAHÃO, C. M. S.; GÂNDARA, J.M.G. A Curitiba dos Restaurantes: Uma análise da evolução dos estabelecimentos de alimentação comercial com base nos registros do Guia Quatro Rodas 1989/2014. Revista Hospitalidade. São Paulo, volume 13, pp. 0828, agosto de 2016 .

Figura 1: Curitiba dividida em bairros.

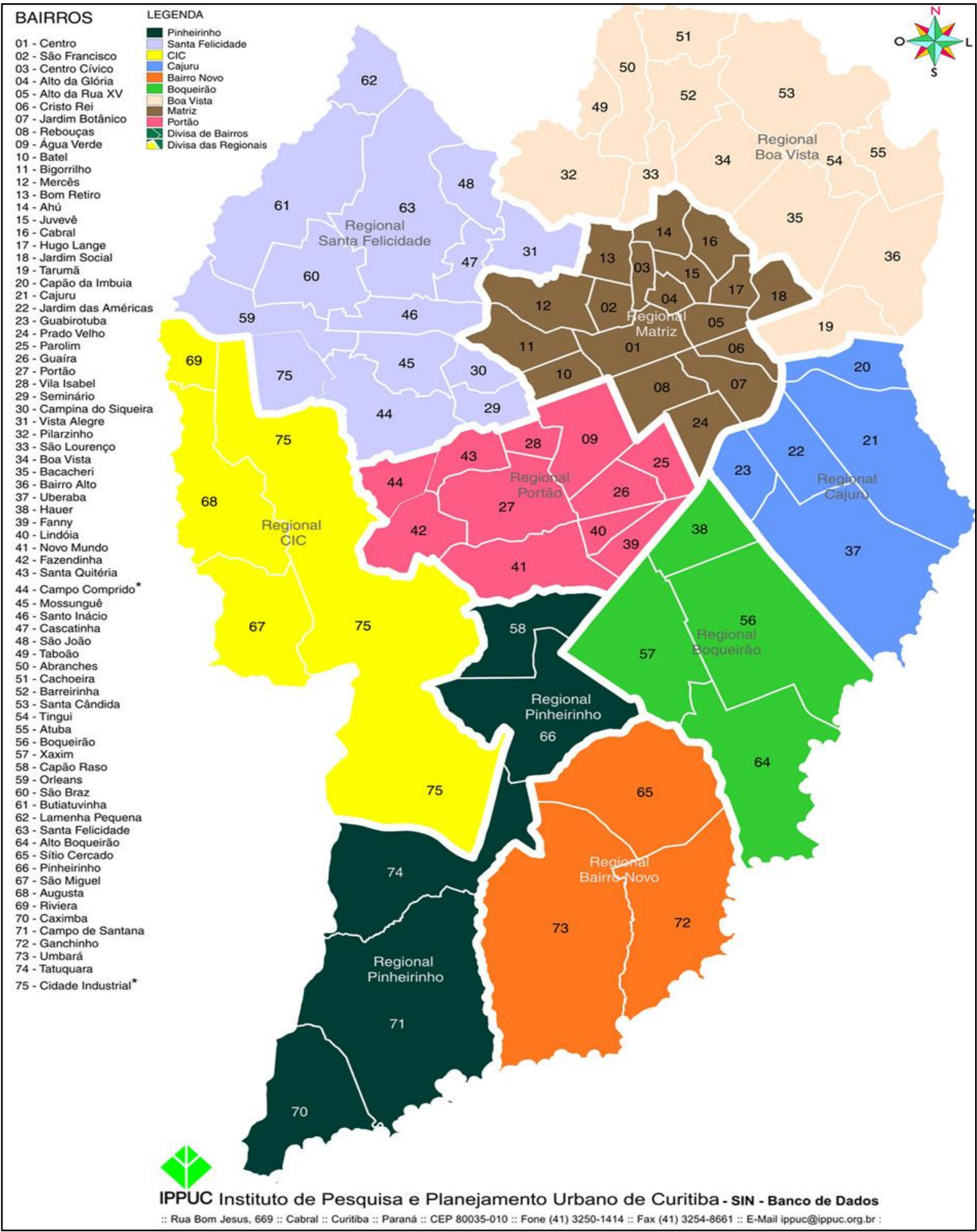

Fonte: IPPUC - Instituto de Pesquisa e Planejamento Urbano de Curitiba (2010). 
BIZINELLI, C; MANOSSO, F.C; ABRAHÃO, C. M. S.; GÂNDARA, J.M.G. A Curitiba dos Restaurantes: Uma análise da evolução dos estabelecimentos de alimentação comercial com base nos registros do Guia Quatro Rodas 1989/2014. Revista Hospitalidade. São Paulo, volume 13, pp. 0828, agosto de 2016.

No que diz respeito à sua formação demográfica, cabe ressaltar que Curitiba é formada por uma diversidade étnica vasta, que lhe confere peculiaridades passíveis de valorização como atrativos. Essas características étnicas estão presentes na paisagem urbana por meio das construções residenciais, nas festas cívicas e religiosas, na dança, na música, na culinária e são representadas em diversos memoriais de imigração e outros espaços públicos, como parques e bosques municipais (PREFEITURA MUNICIPAL DE CURITIBA, 2012).

Tendo ciência disto, vale abordar o que Reichembach (2007) em seu estudo sobre a alimentação na cidade de Curitiba, analisa que a maioria dos restaurantes, em 1981, estavam localizados nas ruas XV de Novembro, Marechal Deodoro, Barão do Rio Branco, Avenida João Negrão e Praça Tiradentes, sendo que a partir das transformações que ocorreram na cidade, novos centros de lazer e restaurantes surgiram, contendo cardápios de cozinha clássica e convencional. Neste ano, segundo a mesma autora, surgiram bares e lanchonetes especializadas no preparo de comida rápida (sanduíches, pizzas em pedaços, entre outros) servida nos balcões, sendo considerado um prelúdio para entrada dos fast food em Curitiba que ocorreu em 1989, com a abertura do primeiro McDonald’s na cidade.

Ao que se refere à localização geográfica dos restaurantes, a mesma pode ser um indicativo para a atração dos consumidores, a partir das especificidades dos locais e do públicoalvo. Ribeiro (2009) apresentou dados referentes à Curitiba, discutindo a atratividade dos bairros através da sua gastronomia, primeiramente, ela cita como exemplo o bairro Batel, que apesar de não ser considerado um bairro gastronômico, possuía cerca de 202 estabelecimentos que comercializam alimentação (MATEOS, KOSLOWSKI E RIBEIRO, 2009) e que vem atraindo um bom número de consumidores na cidade. Por sua vez, o bairro Santa Felicidade, apresentou 63 empreendimentos relacionados ao segmento de alimentação no referido estudo, muitos deles se utilizando de vários serviços simultaneamente (a la carte, disk-entrega, Buffet self service e quilo) (ANDRADE E RIBEIRO, 2009).

Segundo dados do MTE/RAIS, a oferta de serviços de alimentação em Curitiba evidencia a boa quantidade e variedade de restaurantes e similares, totalizando em 2011, mais de 3.500 estabelecimentos, o que inclui todos os tipos de serviços de alimentação fora do lar. Entretanto, como o foco deste estudo é a relação que estes estabelecimentos possuem com o turismo, vale ressaltar que com base nos dados do inventário turístico da cidade constam 575 estabelecimentos. Esta relação de empreendimentos inventariados permite a verificação da 
BIZINELLI, C; MANOSSO, F.C; ABRAHÃO, C. M.

S.; GÂNDARA, J.M.G. A Curitiba dos Restaurantes: Uma análise da evolução dos estabelecimentos de alimentação comercial com base nos registros do Guia Quatro Rodas 1989/2014. Revista Hospitalidade. São Paulo, volume 13, pp. 0828, agosto de 2016.

diversidade de opções gastronômicas que oferta o destino Curitiba, chegando a mais de 25 tipos de especialidades. O que pode ser observado no gráfico a seguir (Figura 2) (PDTIS, 2013):

Figura 2: Quantidade de Restaurantes em função da variedade gastronômica

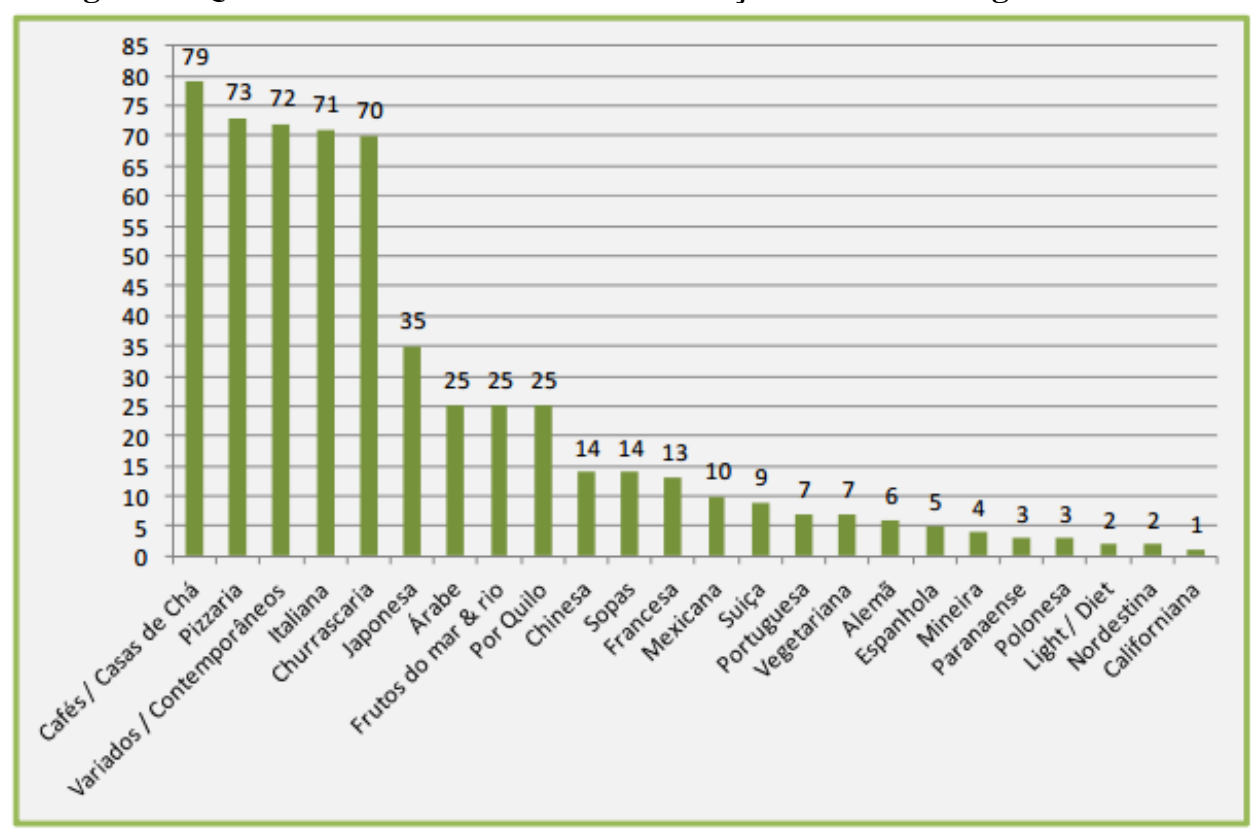

Fonte: PDITIS, 2013.

Ainda segundo o mesmo inventário, dentre as maiores concentrações desses equipamentos pela cidade merecem destaque os bairros Batel, Centro, Água Verde, Santa Felicidade e demais bairros adjacentes, como Centro Cívico, São Francisco e Alto da Rua XV. (PDTIS, 2013). O que pode ser destacado no gráfico a seguir (Figura 3): 


\section{HOSPITALIDADE}

ISSN 1807-975X
BIZINELLI, C; MANOSSO, F.C; ABRAHÃO, C. M. S.; GÂNDARA, J.M.G. A Curitiba dos Restaurantes: Uma análise da evolução dos estabelecimentos de alimentação comercial com base nos registros do Guia Quatro Rodas 1989/2014. Revista Hospitalidade. São Paulo, volume 13, pp. 0828, agosto de 2016.

Figura 3: Concentração territorial dos empreendimentos de alimentação

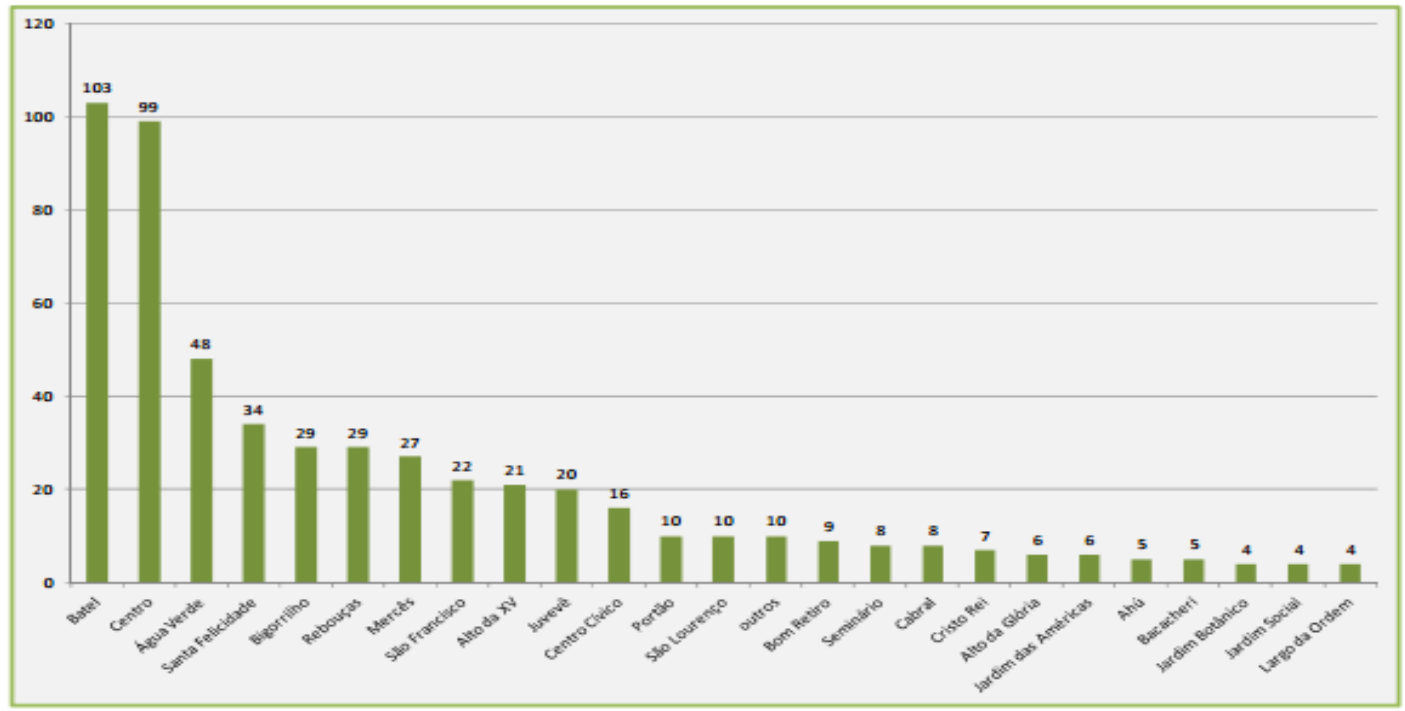

Fonte: PDITIS, 2013.

Ao que diz respeito à concentração dos serviços de alimentação, pode-se dizer que, de certa forma, esta pode proporcionar uma maior organização dos empreendimentos a fim de se qualificar para o atendimento ao público, sejam moradores ou visitantes. Exemplos disso na cidade de Curitiba são: a Praça Espanha que conta, inclusive, com o apoio do Instituto Municipal de Turismo, através de incentivo às ações realizadas pelo grupo empresarial ali presente; outro polo consolidado e com representatividade local é o bairro de Santa Felicidade, conhecido pela oferta de gastronomia italiana e restaurantes de destaque pelo tamanho e história. Além destes, podem ser mencionados alguns polos 'informais', a exemplo da Avenida do Batel, da Rua Itupava (Alto da Rua XV) e do Setor Histórico, que apresentam iniciativas referentes à sua representatividade no cenário gastronômico de Curitiba (PDTIS, 2013). É importante destacar que a cidade, possui em cada um de seus bairros características históricas, urbanas e sociais que geram diferenças quando se aborda as questões alimentares e a atração turística.

Neste contexto, podem ser mencionados alguns autores que, em seus trabalhos, discutiram a temática da alimentação na cidade de Curitiba, sendo estes apresentados no Quadro 01: 

análise da evolução dos estabelecimentos de alimentação comercial com base nos registros do Guia Quatro Rodas 1989/2014. Revista Hospitalidade. São Paulo, volume 13, pp. 0828, agosto de 2016 .

Quadro 1: Pesquisas sobre a Alimentação em Curitiba.
\begin{tabular}{|l|l|}
\hline \multicolumn{1}{|c|}{ Autor / Ano } & \multicolumn{1}{c|}{ Abordagem } \\
\hline Rolim $(1997 ; 2002)$ & $\begin{array}{l}\text { Alimentação e sociabilidade nos bares e restaurantes da cidade de Curitiba, } \\
\text { durante os anos de 1950-1960. }\end{array}$ \\
\hline Gimenes $(2003 ; 2004)$ & $\begin{array}{l}\text { Lazer, consumo simbólico e sociabilidade em bares e casas noturnas de } \\
\text { Curitiba. }\end{array}$ \\
\hline Carvalho (2005) & $\begin{array}{l}\text { Trajetória do desenvolvimento dos estabelecimentos de alimentação na cidade } \\
\text { de Curitiba, entre os anos 1890 e 1940. }\end{array}$ \\
\hline Strobel et al (2005) & Hábitos de consumo alimentar dos curitibanos. \\
\hline Dansky (2008) & $\begin{array}{l}\text { Retrospectiva da evolução dos estabelecimentos de alimentação de Curitiba, } \\
\text { enfatizando o advento do Fast-food. }\end{array}$ \\
\hline Caldart e Bahl (2009) & $\begin{array}{l}\text { Bairro de Santa Felicidade, reduto gastronômico de Curitiba, e sua relação com } \\
\text { o turismo e a transformação do espaço. }\end{array}$ \\
\hline Ribeiro (2009; 2012) & $\begin{array}{l}\text { - Restaurantes por quilo em Curitiba - contextos políticos, sociais e econômicos } \\
\text { (1980-1990). } \\
\text { - Restaurantes comerciais em Curitiba, entre 1970-2000, para traçar perfil da } \\
\text { sociedade em diferentes percepções temporais. }\end{array}$ \\
\hline Reichembach (2007) & $\begin{array}{l}\text { Historia e alimentação: o advento do fast food e as mudanças dos } \\
\text { hábitos alimentares em Curitiba }\end{array}$ \\
\hline Corção (2011) & $\begin{array}{l}\text { Estabelecimentos de alimentação/entretenimento tradicionais da cidade de } \\
\text { Curitiba e caracterização destes espaços como 'espaços de rememoração'. }\end{array}$ \\
\hline Neves et al (2011) & $\begin{array}{l}\text { Receptividade dos setores gastronômico e turístico na cidade de Curitiba, e } \\
\text { expectativas para a Copa do Mundo de 2014. }\end{array}$ \\
\hline Banczek et al (2010) & O comportamento dos consumidores dos restaurantes self-service em Curitiba. \\
\hline Akel (2012) & $\begin{array}{l}\text { A percepção da qualidade da experiência dos consumidores na formação da } \\
\text { reputação online de restaurantes de Curitiba. }\end{array}$ \\
\hline Bizinelli et al (2013) & Experiências de Turismo Cervejeiro em Curitiba, PR. \\
\hline
\end{tabular}

Fonte: Elaborado pelos Autores, 2014.

Os trabalhos mencionados são abordagens distintas (cultural, histórica, econômica, etc.) a respeito da alimentação e temas correlatos na cidade de Curitiba, permitindo um panorama amplo e contribuindo para o presente estudo como fontes de referência.

Com vistas a tudo que foi abordado até o presente momento no referencial teórico, os próximos tópicos abordarão a metodologia de pesquisa, bem como, os resultados oriundos da pesquisa nos Guias Brasil Quatro Rodas.

\section{METODOLOGIA DE PESQUISA}

O estudo realizado teve como objetivo central analisar a dinâmica da distribuição dos restaurantes da cidade de Curitiba, bem como, das categorias de restaurantes presentes nos bairros, utilizando-se do Guia Quatro Rodas englobando um período de 25 anos, sendo considerados para tal os anos de 1989, 2001 e 2014, buscando verificar mais claramente as alterações decorridas em cada período. 
BIZINELLI, C; MANOSSO, F.C; ABRAHÃO, C. M. S.; GÂNDARA, J.M.G. A Curitiba dos Restaurantes: Uma análise da evolução dos estabelecimentos de alimentação comercial com base nos registros do Guia Quatro Rodas 1989/2014. Revista Hospitalidade. São Paulo, volume 13, pp. 0828, agosto de 2016.

Para o alcance de tal objetivo se utilizou como metodologia a pesquisa bibliográfica e documental. A pesquisa bibliográfica, também denominada de revisão literária, é conceituada por Popper (1974), como uma síntese referente aos temas a serem abordados dentro do estudo, trabalhada a partir de uma perspectiva lógica, na qual são apresentados e comentados trabalhos que outros autores produziram sobre o assunto, possibilitando observar as similitudes e as discrepâncias existentes entre o que foi apresentado pelos outros autores.

A pesquisa documental difere da bibliográfica, por se basear em materiais que ainda não receberam 'tratamento analítico' ou, que, podem ser reelaborados em determinado momento. Como exemplo desses documentos podem-se citar os formulários da EMBRATUR, os relatos de viagens, relatórios de pesquisas realizadas anteriormente e dados estatísticos (IBGE) (DENCKER, 1998). Para o referido estudo, utilizaram-se ambas as técnicas ao se discutir os temas apresentados no referencial teórico.

Além das técnicas citadas anteriormente, utiliza-se da análise de conteúdo, que pode ser conceituada como um conjunto de procedimentos de verificação das comunicações que emprega métodos sistemáticos e objetivos da descrição das mensagens presentes no conteúdo a ser pesquisado, esta 'ferramenta' tem como objetivo obter indicadores (quantitativos ou não) que permitam a inferência de conhecimentos relativos às condições de produção e de recepção dessas mensagens (BARDIN, 2009).

A análise de conteúdo foi empregada no exame do Guia Quatro Rodas, para que se pudesse verificar a localização dos restaurantes de Curitiba, apresentados pela publicação, nos anos de 1989, 2001 e 2014, bem como, as categorias dos estabelecimentos presentes na cidade, informações estas, que serão apresentadas em tabelas, referentes a cada ano consultado dos guias. A escolha de utilização do Guia Quatro Rodas se deu por ser considerada uma publicação renomada dentro do segmento de viagens, publicado anualmente, o mesmo oferece sugestões sobre roteiros e informações turísticas a respeito das cidades brasileiras, bem como avalia anonimamente tanto os meios de hospedagem quanto os estabelecimentos, provendo ao leitor, além da avaliação, a localização, os tipos de estabelecimentos e as características daqueles empreendimentos considerados relevantes dentro da cidade a ser visitada (GIMENES, 2009; VILLANUEVA RAMOS, 2010).

Por fim, com base nos apontamentos, serão realizadas a discussão e a análise dos resultados que será utilizada para realizar o emparelhamento, que segundo Laville e Dionne 
BIZINELLI, C; MANOSSO, F.C; ABRAHÃO, C. M. S.; GÂNDARA, J.M.G. A Curitiba dos Restaurantes: Uma análise da evolução dos estabelecimentos de alimentação comercial com base nos registros do Guia Quatro Rodas 1989/2014. Revista Hospitalidade. São Paulo, volume 13, pp. 0828, agosto de 2016.

(1999) é a análise e o cruzamento dos dados encontrados na pesquisa com o referencial teórico do estudo para que o estudo tenha resultados mais consistentes. Nesse sentido, o próximo tópico abordará a análise e a discussão dos resultados da pesquisa.

\section{ANÁLISE E DISCUSSÃO DOS RESULTADOS}

Com a apreciação do que foi discutido até o presente momento, principalmente, no referencial teórico sobre a temática, cabe nesse tópico destacar os principais resultados encontrados ao se buscar alcançar o objetivo proposto: analisar a dinâmica da distribuição dos restaurantes da cidade de Curitiba, nos anos de 1989, 2001 e 2014, a partir da perspectiva do Guia Brasil Quatro Rodas.

Serão apresentadas as categorias dos restaurantes e os bairros onde as mesmas estavam (ao) localizadas. A Tabela 1 apresenta os resultados oriundos do ano de 1989, 2001 e 2014.

Em 1989 pode-se verificar que se destacavam a presença de churrascarias, situadas principalmente no Bairro Batel, Centro e Rebouças. Seguidamente, as pizzarias e a cozinha italiana ganham destaque no guia, contemplando restaurantes, principalmente, em Santa Felicidade e Batel.

Com a análise da Tabela 01, pode-se perceber o que afirma Ribeiro (2009) quando cita que a partir de 1981, surgiram na cidade de Curitiba, bares e lanchonetes especializadas no preparo de comida rápida, localizados principalmente na região central da cidade. Outro ponto a ser salientado é o destaque do bairro Batel, que apesar de não ser considerado um bairro gastronômico pela mesma autora, possui um bom número de estabelecimentos de importância para a atividade turística. Ao que se refere aos resultados oriundos da análise do Guia Brasil de 2001 (Tabela 01, percebe-se restaurantes de comida italiana localizados, prioritariamente, no bairro Batel e Santa Felicidade ganham destaque.

Como citado anteriormente, o bairro Batel e Santa Felicidade continuam ganhando destaque, essa proeminência pode ser analisada a partir do que cita Mateos, Koslowski e Ribeiro (2009) que destacam que o bairro Batel, possui aproximadamente 202 estabelecimentos de alimentação, 
BIZINELLI, C; MANOSSO, F.C; ABRAHÃO, C. M. S.; GÂNDARA, J.M.G. A Curitiba dos Restaurantes: Uma análise da evolução dos estabelecimentos de alimentação comercial com base nos registros do Guia Quatro Rodas 1989/2014. Revista Hospitalidade. São Paulo, volume 13, pp. 0828, agosto de 2016.

Tabela 01: Categorias de Restaurantes de Curitiba: Guia Brasil Quatro Rodas

\begin{tabular}{|c|c|c|c|c|c|c|}
\hline \multirow[t]{2}{*}{ Categoria } & \multicolumn{2}{|r|}{1989} & \multicolumn{2}{|r|}{2001} & \multicolumn{2}{|r|}{2014} \\
\hline & N. & Bairros & N. & Bairros & N. & Bairros \\
\hline Alemã & 02 & São Francisco (2) & 02 & $\begin{array}{l}\text { Água Verde (1), São } \\
\text { Francisco (1). }\end{array}$ & 01 & Água Verde (1) \\
\hline Argentina & & & & & 01 & Centro (1) \\
\hline Asiática & & & & & 01 & Centro (1) \\
\hline Árabe & 01 & Centro (1). & 03 & Centro (2), Batel (1). & & \\
\hline Brasileira & 01 & Centro (1). & & & & \\
\hline Café Colonial & & & 01 & São Francisco (1). & & \\
\hline Chinesa & 04 & $\begin{array}{l}\text { Rebouças (1), Centro } \\
\text { (1), Alto da XV (1), } \\
\text { Bigorrilho (1). }\end{array}$ & 02 & $\begin{array}{l}\text { Água Verde (1), } \\
\text { Bigorrilho (1). }\end{array}$ & & \\
\hline Churrasco/Carnes & 15 & $\begin{array}{l}\text { Batel (2), Juvevê (1), } \\
\text { Centro Cívico (1), } \\
\text { Tarumã (1), Santa } \\
\text { Felicidade (1), } \\
\text { Bigorrilho (1), } \\
\text { Mercês (1), } \\
\text { Rebouças (2), Bom } \\
\text { Retiro (1), Centro } \\
\text { (2), Alto da Glória } \\
\text { (1), Portão (1). }\end{array}$ & 03 & $\begin{array}{l}\text { Campina do Siqueira } \\
\text { (1), Batel (1), Água } \\
\text { Verde (1). }\end{array}$ & 03 & $\begin{array}{l}\text { São Francisco (1); } \\
\text { Seminário (1); Água } \\
\text { Verde (1). }\end{array}$ \\
\hline $\begin{array}{l}\text { Churrasco } \\
\text { (Rodízio) }\end{array}$ & & & 04 & $\begin{array}{l}\text { Centro Cívico (1), } \\
\text { Uberaba (1), Santa } \\
\text { Felicidade (1), Batel } \\
\text { (1). }\end{array}$ & 03 & $\begin{array}{l}\text { Seminário (1); } \\
\text { Rebouças (1); Centro } \\
\text { (1). }\end{array}$ \\
\hline Contemporânea & & & & & 03 & $\begin{array}{l}\text { Batel (1); Centro (1); } \\
\text { Bigorrilho (1). }\end{array}$ \\
\hline Francesa & 01 & Centro (1) & 04 & Centro (3), Batel (1) & 01 & Bigorrilho (1) \\
\hline Indiana & & & & & 01 & Batel (1). \\
\hline Internacional & 04 & $\begin{array}{l}\text { Centro (3), Centro } \\
\text { Cívico (1). }\end{array}$ & & & & \\
\hline Italiana & 10 & $\begin{array}{l}\text { Alto do Cabral (1), } \\
\text { Centro (2), Santa } \\
\text { Felicidade (5), Batel } \\
\text { (1), Pilarzinho (1). }\end{array}$ & 12 & $\begin{array}{l}\text { Batel (4), Seminário } \\
\text { (1), Centro (2), Água } \\
\text { Verde (1), Santa } \\
\text { Felicidade (2), Juvevê } \\
\text { (1), Mercês (1). }\end{array}$ & 07 & $\begin{array}{l}\text { Batel (2); Centro (1); } \\
\text { Água Verde (1); } \\
\text { Rebouças (1); Santa } \\
\text { Felicidade (1); Alto da } \\
\text { XV (1) }\end{array}$ \\
\hline Italiana (Rodízio) & & & 03 & Santa Felicidade (3). & 02 & Santa Felicidade (2). \\
\hline Japonesa & 04 & $\begin{array}{l}\text { Rebouças (1), Centro } \\
\text { (2), Santa Felicidade } \\
\text { (1). }\end{array}$ & 02 & Água Verde (2). & 01 & Água Verde (1). \\
\hline Miúdos & 01 & Centro (1). & & & & \\
\hline Mineira & & & 01 & Centro Cívico (1). & & \\
\hline Nordestina & & & 01 & Vila Isabel (1). & & \\
\hline Panquecas & 01 & Batel (1). & & & & \\
\hline Pescados & 08 & $\begin{array}{l}\text { Cristo Rei (1), Hugo } \\
\text { Lange (1), Santa } \\
\text { Felicidade (1), Batel } \\
\text { (1), São Francisco } \\
\text { (1), Taboão (2), São } \\
\text { Lourenço (1). }\end{array}$ & 05 & $\begin{array}{l}\text { Batel (1), Ahú (1), } \\
\text { São Lourenço (3). }\end{array}$ & 02 & São Lourenço (2). \\
\hline
\end{tabular}


BIZINELLI, C; MANOSSO, F.C; ABRAHÃO, C. M. S.; GÂNDARA, J.M.G. A Curitiba dos Restaurantes: Uma análise da evolução dos estabelecimentos de alimentação comercial com base nos registros do Guia Quatro Rodas 1989/2014. Revista Hospitalidade. São Paulo, volume 13, pp. 0828, agosto de 2016.

\begin{tabular}{|c|c|c|c|c|c|c|}
\hline Pizzas & 10 & $\begin{array}{l}\text { Batel (4), Mercês (2), } \\
\text { Juvevê (1), São } \\
\text { Francisco (1), Centro } \\
\text { (1), Cristo Rei (1). }\end{array}$ & 02 & Batel (1), Centro (1). & 04 & Batel (2); Centro (2). \\
\hline Polonesa & 01 & Batel (1). & 01 & Batel (1). & & \\
\hline Portuguesa & 02 & $\begin{array}{l}\text { Mercês (1), Centro } \\
\text { (1). }\end{array}$ & 03 & $\begin{array}{l}\text { Mercês (1), Cabral } \\
\text { (1), Batel (1). }\end{array}$ & 01 & São Francisco (1). \\
\hline Regional & & & 01 & São Francisco (1). & & \\
\hline Sopas & 03 & Batel (2), Centro (1). & 02 & Centro (2). & & \\
\hline Suíça & 02 & $\begin{array}{l}\text { Mercês (1), Centro } \\
\text { (1). }\end{array}$ & & & & \\
\hline Vegetariana & 02 & Centro (2). & & & & \\
\hline Variada & & & 07 & $\begin{array}{l}\text { Santa Felicidade (1), } \\
\text { Jardim Schaffer (1), } \\
\text { Centro (2), São } \\
\text { Francisco (1), Jardim } \\
\text { Botânico (1), Mercês } \\
\text { (1). }\end{array}$ & 09 & $\begin{array}{l}\text { São Francisco (2); } \\
\text { Juvevê (1); Bigorrilho } \\
\text { (1); Batel (3); Alto da } \\
\text { XV (1). }\end{array}$ \\
\hline Variada (Buffet) & & & & & 04 & $\begin{array}{l}\text { Batel (1); Seminário } \\
\text { (1); Ecoville (1); } \\
\text { Centro (1). }\end{array}$ \\
\hline Comidinhas & & & & & 13 & $\begin{array}{l}\text { Alto da XV (2); } \\
\text { Ecoville (1); Paço da } \\
\text { Liberdade (1); Centro } \\
\text { (2); Batel (3); Jardim } \\
\text { Social (1); Centro } \\
\text { Cívico (1); Bigorrilho } \\
\text { (1). }\end{array}$ \\
\hline Bares & 07 & $\begin{array}{l}\text { São Francisco (3), } \\
\text { Centro (2), Batel (2). }\end{array}$ & & & 09 & $\begin{array}{l}\text { Centro (3); São } \\
\text { Francisco (1); Batel } \\
\text { (3); Alto da XV (1); } \\
\text { Mercês (1). }\end{array}$ \\
\hline Boates & 07 & $\begin{array}{l}\text { Centro (3), Batel (3), } \\
\text { Alto do Cabral (1). }\end{array}$ & & & & \\
\hline Café & 02 & Centro (2). & & & & \\
\hline
\end{tabular}

Fonte: Elaborado pelos autores, 2014.

Analisando a Tabela 1 pode-se inferir que a alimentação em Curitiba apresentada no Guia Brasil Quatro Rodas engloba repetidamente alguns pontos dentro do cenário da alimentação comercial na cidade, recebendo destaque os bairros Centro, Santa Felicidade e Batel, onde há uma concentração permanente de estabelecimentos de alimentação, durante o período de tempo analisado (1989-2014). Apesar de existir um bom número de restaurantes no centro da cidade no ano de 1989, esses estabelecimentos foram diminuindo com o passar dos anos, corroborando com esse viés, algumas preocupações pertinentes surgem calcadas nas tendências dos laços tradicionais entre o comércio - em especial o pequeno comércio varejista -, e os centros das cidades estarem enfraquecendo nos últimos anos. Nesta conjuntura, Reichembach (2007), em seu estudo sobre a alimentação na cidade de Curitiba, analisa que a maioria dos restaurantes, em 
BIZINELLI, C; MANOSSO, F.C; ABRAHÃO, C. M. S.; GÂNDARA, J.M.G. A Curitiba dos Restaurantes: Uma análise da evolução dos estabelecimentos de alimentação comercial com base nos registros do Guia Quatro Rodas 1989/2014. Revista Hospitalidade. São Paulo, volume 13, pp. 0828, agosto de 2016.

1981, localizavam-se nas ruas XV de Novembro, Marechal Deodoro, Barão do Rio Branco, Avenida João Negrão e Praça Tiradentes, ou seja, no centro da cidade, sendo que foi somente a partir das transformações que ocorreram em Curitiba, que novos restaurantes surgiram, contendo cardápios de cozinha clássica e convencionais, com localizações distintas, como Batel e Santa Felicidade.

Observando o que foi obtido com a pesquisa nos guias, apresentado na Tabela 01, podese verificar que a variedade de tipologias de estabelecimentos é diversa, contemplando os mais distintos tipos de culinária, encontrando-se em consonância ao que é apresentado na Figura 2.

Outro ponto a ser ressaltado, representado na Figura 3 e corroborado pela pesquisa realizada nos guias turísticos, é a quantidade de estabelecimentos presentes em alguns bairros da cidade, que ao longo dos anos observados vem sendo frequente ou crescente. Fato este, que demonstra a conformação de alguns pontos de destaque gastronômico na cidade, conforme apresentado pelo PDTIS (2013), em que recebem destaque os bairros Batel, Centro, Água Verde, Santa Felicidade e demais bairros adjacentes, como Centro Cívico, São Francisco e Alto da Rua XV. Lembrando que a amostra considera nas pesquisas e documentos do PDTIS (2013) é baseada, sobretudo, no inventário da cidade de Curitiba, analisando desta forma, aquilo que é de interesse turístico para a cidade, fazendo com que se perceba a consonância do que foi verificado na presente pesquisa e no que vem sendo trabalhado dentro do âmbito turístico da cidade, ao que se refere à divulgação e conformação de sua gastronomia.

\section{CONSIDERAÇÕES FINAIS}

Os estabelecimentos comerciais de alimentação são considerados relevantes dentro da atividade turística, pois pode ser avaliado tanto como um atrativo turístico, a partir da perspectiva da gastronomia como forma de se valorizar a cultura, tanto como um equipamento turístico. Em ambos os casos, os restaurantes são vistos dentro da atividade como uma forma de atração de turistas para uma determinada localidade. Portanto, o estudo da dinâmica da distribuição espacial desses empreendimentos é imprescindível, pois faz com que se compreenda de que forma a cidade se configura para o recebimento dos turistas e de que forma a oferta da mesma vem sendo trabalhada. Cabe lembrar, ainda, o objetivo central desse estudo se pautou na análise da distribuição espacial dos restaurantes da cidade de Curitiba presentes no Guia Brasil Quatro Rodas dos anos de 1989, 2001 e 2014, para que se pudesse observar a evolução dos restaurantes 
BIZINELLI, C; MANOSSO, F.C; ABRAHÃO, C. M. S.; GÂNDARA, J.M.G. A Curitiba dos Restaurantes: Uma análise da evolução dos estabelecimentos de alimentação comercial com base nos registros do Guia Quatro Rodas 1989/2014. Revista Hospitalidade. São Paulo, volume 13, pp. 0828, agosto de 2016.

dentro dos bairros de Curitiba, em números, bem como nas categorias de estabelecimentos que se destacaram nesses 25 anos observados.

Como resultados das referidas pesquisas percebeu-se a predominância de restaurantes nos bairros do Centro, Batel e Santa Felicidade, sendo que há variações entre cada ano. Dentro das categorias se destacaram as pizzarias, as churrascarias e a comida italiana, com maior número de empreendimentos distribuídos pela cidade. Também se nota uma variação nas tendências de categorias dos estabelecimentos de alimentação comercial a cada edição analisada, no caso de 1989, além das categorias mencionadas, destacaram-se restaurantes de pescados, casas de chá e confeitarias; em 2001, observou-se crescimento do número de estabelecimentos de alimentação com cozinha 'variada'; e em 2014, nota-se a forte tendência das 'comidinhas', como novo tipo de estabelecimento-tendência, bem como, a permanência das cozinhas variadas em destaque.

Pode-se salientar que a existência de locais que ofertam uma alimentação de qualidade, localizados tanto próximos ao trabalho, quanto à moradia dos indivíduos, fez com que a alimentação fora do lar se tornasse um importante segmento da economia curitibana, fazendo com que mais estabelecimentos buscassem uma maneira de se divulgar. Os guias turísticos, por sua vez, como uma dessas ferramentas de divulgação, tornaram-se deveras importantes, pois são considerados um relevante instrumento para a tomada de decisão do turista ao escolher determinada localidade ou empreendimento para concretização de suas experiências turísticas (FERREIRA, 2011; RIBEIRO, 2010).

Cabe ressaltar que o presente artigo trabalhou apenas alguns dos aspectos apresentados no Guia Quatro Rodas sobre os restaurantes (localização e categorias), podendo ser utilizados em estudos futuros outros motes relevantes discutidos no documento, como: o nível de conforto dos estabelecimentos, a qualidade das cozinhas e o preço praticado.

\section{REFERÊNCIAS BIBLIOGRÁFICAS}

AKEL, G.M. Reputação Online no Mundo da Alimentação Comercial: Um estudo comparativo entre Ourense (Espanha) e Curitiba (Brasil). Dissertação de Mestrado apresentada para obtenção de título de Planificación y Dirección del Turismo Interior y de Salud. Facultad de Ciencias Empresariales y Turismo. Universidade de Vigo, Ourense, Espanha, 2012.

ALVES, L. A; RIBEIRO FILHO, V. Reestruturação urbana das atividades de comércio e serviços em Uberlândia - MG. Disponível em: <

http://www.seer.ufu.br/index.php/horizontecientifico/article/viewFile/4199/3143>. Acesso em: 18 jun. 2014, 2008. 
BIZINELLI, C; MANOSSO, F.C; ABRAHÃO, C. M. S.; GÂNDARA, J.M.G. A Curitiba dos Restaurantes: Uma análise da evolução dos estabelecimentos de alimentação comercial com base nos registros do Guia Quatro Rodas 1989/2014. Revista Hospitalidade. São Paulo, volume 13, pp. 0828, agosto de 2016.

ANDRADE, R. S.; RIBEIRO, C. S. G. Perfil dos estabelecimentos que produzem e distribuem alimentos no bairro Santa Felicidade: uma abordagem historiográfica e alimentar, 2009.

BAHL, M; GIMENES, M. H. G; NITSCHE, L. B. Territorialidade gastronômica: as cozinhas regionais como forma de mediação do homem com o meio e como atrativo turístico. Revista Geográfica de América Central, v. 2, p. 1/47E-16, 2011.

BANCZEK, H. F. L; VAZ, C. R; MONTEIRO, S. A. Comportamento dos consumidores em self-service no município de Curitiba. Revista Brasileira de Tecnologia Agroindustrial, v. 4, n. 1, p. 29-41, Ponta Grossa, 2010.

BARDIN, L. Análise de Conteúdo. Lisboa, Portugal; Edições 70, LDA, 2009.

BENI, M. C. Análise estrutural do turismo. São Paulo: Senac, 1998.

BIZINELLI, C. Enoturismo e Turismo de Experiência: Novas possibilidades para a inclusão de pessoas com deficiência visual. Trabalho de Conclusão de Curso em Turismo. Curitiba: UFPR, 2011.

BIZINELLI, C.; MANOSSO, F. C.; GÂNDARA, J. M. G.; VALDUGA, V. Experiências de Turismo Cervejeiro em Curitiba (PR). Revista Rosa dos Ventos, v. 05, p. 349-375, 2013.

CALDART, M; BAHL, M. Bairro de Santa Felicidade - Curitiba, a influência do turismo na transformação do espaço urbano local. Revista Geografar, Resumos do VII Seminário Interno de Pós-Graduação em Geografia, Curitiba, 2009.

CARVALHO, D. A. Das casas de pasto aos restaurantes: os sabores da velha Curitiba (1890 1940). Dissertação de Mestrado em História. Curitiba: UFPR, 2005.

CORÇÃO, M. De espaço de inovação a lugar de tradição: Bar Palácio como espectador e ator da dinâmica urbana de Curitiba (1930-2006). Tempo e Argumento, v. 3, n. 1, p. 130 - 147, Florianópolis, 2011.

CRUZ, R. C. A. Introdução a Geografia do Turismo. São Paulo: Rocca, 2a Ed, 2003.

DANSKY, M. T. R. História e alimentação: o advento do fast food em Curitiba. Historia Actual Online, v. 17, p. 19-29, 2008.

DENCKER, A. F. M. Pesquisa em turismo: planejamento, métodos e técnicas, São Paulo: Futura, 1998.

ESPINOSA SEGUÍ, A. I. Amenazas y nuevas estrategias del comercio de centro urbano: el caso de Alicante. Boletín de la Asociación de Geógrafos Españoles, v.38, p. 153-174, 2003.

FAGLIARI, G. S. Turismo e alimentação: análises introdutórias. São Paulo: Roca, 2005.

FRATUCCI, A. C. A dimensão espacial nas políticas públicas brasileiras de turismo: as possibilidades das redes regionais de turismo. Tese de Doutorado em Geografia. Niterói: UFF, 2008.

GÂNDARA, J. M. G.; GIMENES, M. H. S. G.; MASCARENHAS, R. G. Reflexões sobre o Turismo Gastronômico na perspectiva da sociedade dos sonhos. In: PANOSSO NETTO, A.; 
BIZINELLI, C; MANOSSO, F.C; ABRAHÃO, C. M. S.; GÂNDARA, J.M.G. A Curitiba dos Restaurantes: Uma análise da evolução dos estabelecimentos de alimentação comercial com base nos registros do Guia Quatro Rodas 1989/2014. Revista Hospitalidade. São Paulo, volume 13, pp. 0828, agosto de 2016.

Ansarah, M. G. (Org.). Segmentação do mercado turístico - estudos, produtos e perspectivas. Barueri: Manole, 2009.

GIMENES, M. H. S. G. Lazer e Prazer: o consumo simbólico e a vivência da sociabilidade em bares e casas noturnas no início do século XXI na cidade de Curitiba, Paraná. Dissertação de Mestrado em Sociologia. Curitiba: UFPR, 2003.

Bares e casas noturnas: um estudo exploratório sobre consumo e sociabilidade. Turismo em Análise, São Paulo, v. 15, n.1, p. 73-88, 2004.

GIMENES, M. H. S. G. O uso turístico das comidas tradicionais: algumas reflexões a partir do Barreado, prato típico do litoral paranaense (Brasil). Turismo e Sociedade, v. 2, p. artigo n. 1, 2009.

GODOY, C. G. M. Comércio e prestação de serviços a varejo no sistema urbano - Caso: Município Cercado, Cochabamba/Bolívia. Dissertação de Mestrado em Arquitetura Planejamento Urbano e Regional. Porto Alegre: UFRGS, 2010.

IBGE - Instituto Brasileiro de Geografia E Estatística. Dados do Censo 2010 publicados no Diário Oficial da União, 4 nov. 2010. Disponível em:

<http://www.censo2010.ibge.gov.br/dados_divulgados/index.php?uf=41>. Acesso em: 18 jun. 2014.

INMOBRASIL. Overview do turismo no Brasil. Disponível em: <http://www.inmo brasil.com/informes_tecnicos/1/4.pdf >. Acesso em 18 jun. 2014.

IPPUC - Instituto De Pesquisa E Planejamento Urbano De Curitiba (2010). Curitiba em dados. Disponível em:

<http://ippucweb.ippuc.org.br/Bancodedados/Curitibaemdados/Curitiba_em_dados_Pesquisa.ht m>. Acesso em: 18 jun. 2014.

KNAFOU, R. Turismo e território: por uma abordagem científica do turismo. In:

RODRIGUES, A. Turismo e geografia: reflexões teóricas e enfoques regionais. São Paulo: Hucitec, p. 62-74, 2001.

LAMAS, J. M. R. G. Morfologia urbana e desenho da cidade. 2.ed. São Paulo: Fundação Calouste Gulbenkian e Fundação para Ciência e a Tecnologia, 2000.

LAVILLE, C.; DIONNE, J. A construção do saber: manual de metodologia da pesquisa em ciências humanas. Porto Alegre: Editora Artes Médicas Sul Ltda.: Belo Horizonte: Editora UFMG, 1999.

LOUZADA, J. D. Gastronomia.gov.br. Trabalho apresentado ao curso de pós-graduação latu sensu em Gastronomia como empreendimento - CET (Centro de excelência em Turismo), Universidade de Brasília, Brasília, 2006.

MASSEY, D. Pelo espaço: uma nova política da espacialidade. Rio de Janeiro: Bertrand Brasil, 2008.

MATEOS, D. B.; KOSLOWSKI, R. L. RIBEIRO, C. S. G. Perfil dos estabelecimentos que produzem e distribuem alimentos no bairro Batel - Curitiba, PR, 2009.

MOESCH, M. M. Epistemologia social do Turismo. Tese de Doutorado em Ciências da Comunicação. São Paulo: Universidade de São Paulo. 2004. 
BIZINELLI, C; MANOSSO, F.C; ABRAHÃO, C. M. S.; GÂNDARA, J.M.G. A Curitiba dos Restaurantes: Uma análise da evolução dos estabelecimentos de alimentação comercial com base nos registros do Guia Quatro Rodas 1989/2014. Revista Hospitalidade. São Paulo, volume 13, pp. 0828, agosto de 2016.

NEVES, I. A; SEMPREBOM, E; LIMA, A. A. Copa 2014: expectativa e receptividade dos setores hoteleiro, gastronômico e turístico na cidade de Curitiba. In: Anais do XIV Simpósio de Administração da Produção, Logística e Operações Internacionais - SIMPOI, São Paulo, 2011.

NÖRR STIEFENHOFER LUTZ. CURTIS - Comprehensive Urban Retail Trade Improvement Strategy. In: Report. Berlin: Deutscher Verband für Wohnungswesen, Städtebau und Raumordnung. V. 8, 2006.

OJIMA, R. A produção e o consumo do espaço nas aglomerações urbanas brasileiras: desafios para uma urbanização sustentável. In: XV Encontro Nacional de Estudos Populacionais ABEP, Caxambú, 2006.

ONFRAY, M. A razão gulosa: filosofia do gosto. Rio de Janeiro: Ed. Rocco, 1999.

PÍCOLLO, D. R. Distribuição espacial da hotelaria de rede no estado do Paraná. Dissertação apresentada para obtenção do título de Mestre no Programa de Pós Graduação de Geografia. Curitiba: UFPR, 2011.

POPPER, K. A lógica da pesquisa científica. São Paulo: Cultrix, 1974.

PDTIS CURITIBA. Plano de Desenvolvimento Integrado do Turismo Sustentável da Área Turística de Curitiba-PR, 2013.

Prefeitura Municipal De Curitiba. Perfil de Curitiba. Disponível em< http://www.curitiba.pr.gov.br/conteudo/perfil-da-cidade-de-curitiba/174>. Acesso em: 27 jul. 2013.

PROCOPIUCK, M; DJALO, A. B. Comércio como fator de coesão dos centros urbanos: caso da revitalização comercial do centro de Curitiba. Turismo Visão e Ação, v. 10, nº 03, p. 313 333, 2008.

REICHEMBACH, M. T. Historia e alimentação: o advento do fast food e as mudanças dos hábitos alimentares em Curitiba (1960-2002). Tese de doutorado em História, Universidade Federal do Paraná, 2007.

RIBEIRO, C. S. G. Vale quanto pesa: os restaurantes por quilo em Curitiba - contextos sociais, políticos e econômicos (1980-1990), 2009. Disponível em: < http://www.historiadaalimentacao.ufpr.br/artigos/Artigos_PDF/Artigo\%20Cilene\%20Ribeiro.p df>. Acesso em: 18 jun. 2014.

Tudo pronto: o comer fora e o prazer reinventado - Curitiba (1970-2000), 2012. Tese de Doutorado em História. Curitiba: UFPR.

ROLIM, M. C. M. B. Gosto, prazer e sociabilidade: bares e restaurantes de Curitiba - 1950-60. Tese de Doutorado em História. Curitiba: UFPR, 1997. 2002.

A Curitiba dos Bares e Restaurantes: 1950-1960. Percurso, v. 1, p. 31-42, Curitiba,

SANTOS, M. Espaço e método. São Paulo: Nobel, 1985.

Espaço e método. 4. Ed. São Paulo: Nobel, 1997. 
BIZINELLI, C; MANOSSO, F.C; ABRAHÃO, C. M. S.; GÂNDARA, J.M.G. A Curitiba dos Restaurantes: Uma análise da evolução dos estabelecimentos de alimentação comercial com base nos registros do Guia Quatro Rodas 1989/2014. Revista Hospitalidade. São Paulo, volume 13, pp. 0828, agosto de 2016.

SANTOS, J. L. J; SERPA, A. A produção espacial do comércio e dos serviços nas periferias urbanas: um estudo de caso em Salvador. Revista Geousp, São Paulo-SP, v. 8, p. 45-65, 2000.

SCHLÜTER, R. G. Gastronomia e turismo. São Paulo: Aleph, 2003.

STROBEL, J; HASTREITER, S. T; DEGÁSPARI, C. H; BAPTISTA, P. P. Hábitos de consumo alimentar dos curitibanos. Visão Acadêmica, v.6, n.2, Curitiba, 2005.

VILLANUEVA RAMOS, S. E. A dinâmica da localização da hotelaria curitibana no período de 1966 a 2008. Tese apresentada para a obtenção do Título de Doutor no Programa de Pós Graduação em Geografia. Universidade Federal do Paraná, Paraná, 2010.

Aplicação do modelo da hierarquia da localização dos hotéis de Egan e Nield na cidade de Curitiba - PR. In: VIII Seminário da Associação Nacional Pesquisa e Pós-Graduação em Turismo - ANPTUR, Balneário Camboriú, 2011.

\section{Recebido em 09/11/2014}

Reavaliado em 18/08/2015

Aprovado em 08/06/2016 